\title{
Patella kırıklarında kaynamama ve gecikmiş kaynama konusunda güncel literatürün değerlendirilmesi -güncel tedavi yaklaşımları
}

\author{
Evaluation of current literature on non-union and delayed union in patellar fractures \\ -current treatment approaches
}

\author{
Gökhan Özkazanlı, Hakan Başar
}

Sağlık Bilimleri Üniversitesi Gaziosmanpaşa Taksim Eğitim ve Araştırma Hastanesi, Ortopedi ve Travmatoloji Kliniği, İstanbul

Patella kırıklarında kaynamama ve gecikmiş kaynama nadir görülen bir durumdur. İhmal edilmiş, kay-nama gecikmesi olan veya kaynamamış kırıklarda tedavide temel amaç ekstansör mekanizmanın yeni-den oluşturulup fonksiyonel kapasitenin arttırılmasıdır. Kaynamamanın nadir görülmesi nedeniyle te-davisinde standart bir yöntem yoktur. Hastaların beklentisi, kaynamama nedeni, önceden geçirilmiş cerrahi ve kaynamamaya yol açan nedenlere göre tedavi stratejisi belirlenir. Düşük beklentisi olan fonk-siyonel kapasitesi az veya cerrahi kabul etmeyen hastalarda konservatif tedavi tercih edilirken, yüksek fiziksel kapasite beklentisi olan hastalarda cerrahi tedavi tercih edilir. Cerrahide çoğunlukla açık redüksi-yon ve internal tespit yöntemleri tercih edilirken, çok parçalı, tespit uygulanamayan alt ve üst uç kırıkla-rında patellektominin biyomekanik etkileri de göz önüne alınarak, kısmi patellektomi tercih edilebilir. İhmal edilmiş patella kırıklarında ayrışma primer tespit yapılamayacak kadar çok ise iki aşamalı yöntem-ler veya kuadriseps uzatma ile beraber tespit, tedavi seçenekleridir.

Anahtar sözcükler: patella kırıları; kaynamama; gecikmiş kaynama
Non-union and delayed non-union in patella fractures are very uncommon. The main goal in treat-ment of the neglected, delayed or non-union of patellar fracture is restoring the extensor mechanism and improving the functional capacity. There is no standard treatment method since non-union is scarce. Teratment strategy is based on the patients expectation, the reason for nonunion and previ-ous surgery. Conservative treatment can be the first option for low demanding patients with low func-tional capacity, while surgery can be the choice for high demanding patients with high functional capaci-ty. Open reduction and internal fixation is the most common method of choice. Partial patellectomy can be performed in multifragmental and upper pole fractures taking into consideration the biome-chanic effects of patellectomy. For the neglected and displaced fractures with a gap which could not be fixed primarly, two staged surgery or quadriceps lengthening can be the choice for treatment.

Key words: patellar fractures; non-union; delayed union
P atella insan vücudunun en büyük sesamoid kemiğidir. Patella kırıkları tüm kırıklar içinde \%1 oranında görülür. Yeri ve subkutan yerleşimi nedeniyle, direkt travmaya karşı korumasızdır. ${ }^{[1]}$ Yüksek ve düşük enerjili travmayla kırık gerçekleşebilir. Yaşlı ve osteoporozlu hastalarda basit düşme en sık neden iken, gençlerde araç içi ve dışı motorlu araç kazaları sonrasında görülebilir. ${ }^{[2]}$ Açık kırıklarda kaynamama ve enfeksiyon oranları daha yüksek olarak bildirilmiştir (\%7). ${ }^{[3]}$ Patella kırıklarında gecikmiş kaynama ve kaynamama çok nadir görülür. İmmobilizasyon ve cerrahi tedavi ile, nerdeyse tüm kırıklarda kaynama elde edilebilmektedir. ${ }^{[4]}$ Patella kırıklarında konservatif tedavi, ayrışmamış kırıklarda ve ekstansör mekanizmanın bozulmadığı kırıklarda uygulanır. ${ }^{[5]}$ Cerrahi tedavi endikasyonları ise; ekstansör mekanizmada bozulma, kırık hattında 2-3 mm basamaklaşma ve 1-4 mm'den fazla ayrışmadır. ${ }^{[5]}$ ihmal edilmiş patella kırıklarında kaynamama özellikle az gelişmiş ülkelerde görülmektedir ancak ne kadar sıklıkla görüldüğü bildirilmemiştir. ${ }^{[6,7]}$ inmal edilmiş patella kırıklarında parçalar arasında fibrozis gelişmesi nedeniyle, diz ekstansör mekanizması kısmen de olsa çalışan hastalar tedavi için başvurmayabilmektedirler. Transvers kırıklarda, kuadrisepsin güçlü traksiyon etkisi ile kırık parçalar arasında fibrozis gelişemeyecek kadar ayrışmış ve diz

- Illetişim adresi: Op. Dr. Gökhan Özkazanlı, Dereboyu Cad. Saadet Sok. No:1, Mecidiye Mah., Ortaköy, İstanbul Tel: 0532 - 4030120 e-posta: drgokhan@hotmail.com

- Geliş tarihi: 1 Kasım 2017 Kabul tarihi: 1 Kasım 2017 
ekstansör mekanizması çalışmayan hastaların tedavi için başvurduğu görüşü bildirilmiştir. ${ }^{[6]}$ Kaynamama ve gecikmiş kaynama, cerrahi tedavi edilen tüm kırıkların \%2,7-12,5'inde görülür. ${ }^{[8]}$ Tedavi görmemiş, belirgin ayrışmış, ekstansör mekanizması çalışmayan hastalarda kaynamama tanısı kolaylıkla konulurken, konservatif veya cerrahi tedavi görmüş hastalara ne kadar sürede iyileşme beklendiği ve ne zaman kaynama gecikmesi tanısı konulacağı konusunda, insidansın çok düşük olması nedeniyle, kesin bir görüş birliği yoktur. Özellikle, cerrahi tedavi edilmiş hastalarda kaynamama ve implant yetmezliği ayrımını yapmak oldukça güçtür. ${ }^{[9]}$ Cerrahi tespit yöntemlerinin karşılaştırıldığı çalışmalarda izole K-teli ile tespitin en sık yetmezliğe neden olduğu bilinmektedir. Kaynamama; erkek hastalarda, açık kırıklarda, transvers kırıklarda ve alçı tedavisinde daha yüksek olarak bildirilmiştir. ${ }^{[8]}$ Tanı, direkt grafilerde kırık hattında kaynama bulgusu olmaması, güçsüzlük, dizin boşalması, merdiven çıkmada zorluk eklem hareket açıklığında azalma saptanması ile konur. Tedavi şekline karar vermede; hastanın fonksiyonel beklentileri, kaynamamaya yol açan nedenler, total patellektominin biyomekanik etkileri, ekstansör mekanizmanın sağlam olması ve ileride artroplasti ameliyatı olasılı̆̆ göz önüne alınmalıdır.

\section{KLINIK BULGULAR}

Patella kırıklarındaki gecikmiş kaynama ve kaynamamada en sık görülen semptomlar, güçsüzlük ve dizde boşalma hissidir. Merdiven çıkmada zorlanma ve diz hareketlerinde kısıtlılık da bildirilmiştir. ${ }^{[8]}$ ihmal edilmiş kırıklarda belirgin kaynamama ve kırık hattında ayrışma var ise, hasta ekstansör mekanizmanın çalışmamasına bağlı gelişen bulgular ile başvurur. ${ }^{[7]}$

Patella kırıklarında kaynamama, erkeklerde kadınlara oranla daha yüksek oranda görülmektedir; ortalama görülme yaşı 38'dir. ${ }^{[10,11]}$ Açık kırıklarda, transvers ve parçalı kırıklarda, kaynamama ve kaynamada gecikme daha sık görülmektedir. En sık görülen kırık mekanizması, diz üzerine düşme şeklinde tarif edilmiştir. ${ }^{[11,12]}$

Günümüzde patella kırıkları cerrahi olarak başarılı bir şekilde tedavi edilmektedir. Kaynamama ve implant yetmezliği oranları oldukça düşüktür $(\% 1,5-12) \cdot{ }^{[3,13]}$ Patella kırıklarının cerrahi tedavisinde kullanılan birçok tespit yöntemi vardır. Güncel cerrahi seçenekler; K-telleri ile tespit, serklaj, K-telleri ve serklaj ile zuggurtung, periserklaj ve zuggurtung, vida ile tespit, emilmeyen dikiş materyalleri ile tespit, plak vida ile tespit ve çeşitli tespit yöntemlerinin beraber kullanımı sayılabilir. K-teli ve K-teli - serklaj telleri ile tespitin en sık yetmezliğe giden ve implanta ait problemler nedeniyle yeniden ameliyata neden olan cerrahi teknik olduğu bilinmektedir. ${ }^{[3,13]}$

\section{TEDAVI SEÇENEKLERi}

\section{Konservatif Tedavi}

Belirgin ayrışması olmayan, ekstansör mekanizması çalışan, ancak semptomatik olan düşük beklentili ve cerrahi tedaviyi kabul etmeyen hastalar için ilk seçenektir. Konservatif tedavi; gözlem, aktivite değişikliği, fizik tedavi ve ağrıyı azaltıcı yöntemleri içerir. Klassen ${ }^{[12]}$, 20 hastanın yedisini konservatif olarak takip etmiş ve fonksiyonel sonuçlarda artma saptamıştır. Tüm hastalarda radyolojik iyileşme elde edememesine rağmen minimal semptomatik gecikmiş kaynamada ve kaynamamada ilk seçenek olarak tavsiye etmekte, semptomatik hastalarda cerrahi tedavi önermektedir.

\section{Cerrahi Tedavi}

Fonksiyonel beklentisi yüksek olan, belirgin semptomatik, diz ekstansör mekanizmanın çalışmamasına ait semptomları olan, ihmal edilmiş ayrışmış ve kaynamamış kırıklarda cerrahi ilk seçenektir. Tedavide amaç, ekstansör mekanizmanın yeniden oluşturulması ve patellanın korunmaya çalışılmasıdır. Kaynamama ve gecikmiş kaynamada kullanılan cerrahi yaklaşım yöntemi, olguların neredeyse tamamında, primer kırıklarda uygulanan tespit yöntemleri ile aynıdır. Total veya kısmi patellektomi kırığın tespit yapılamayacak kadar parçalı, enfekte, patella tümörleri ve tespit edilemeyen kaynamamasında tercih edilebilecek bir seçenektir. Her ne kadar amaç patellanın korunması olsa da, kısmi patellektomi ile tespitin benzer sonuçları olduğu da bildirilmiştir (Şekil 1). ${ }^{[14]}$ Patellektomi sonrasında hareket kısıtlılığı, diz instabilitesi, ekstansör mekanizmada belirgin güç kaybı, yürüme ve merdiven çıkmada zorluk yaşanması nedeniyle, patellektomi en son tercih edilen kurtarıcı bir cerrahi yöntemdir. Patella kırıklarında geç kaynama ve kaynamamada kemik grefti kullanımı konusunda, bildirilen birkaç olgu dışında ayrıntılı bilgi bulunmamaktadır. Kemik grefti, olguya özgü karar verilerek kullanılabilir. ${ }^{[12,15]}$ Belirgin ayrışması olan ihmal edilmiş patella kırıklarında temel problem, kuadriseps kasındaki kontraktür ve buna bağı kırık hattındaki ayrılmadır. İhmal edilmiş patella kırıklarının azlığı nedeniyle, uygulanan cerrahi tedavi yöntemleri olgu sunumlarıyla sınırlıdır. Kuadriseps cerrahi yöntem ile uzatılarak redüksiyon sağlanabileceği ve fonsiyonel sonuç elde edilebileceği bildirilmiştir. ${ }^{[16]}$ Kuadrisepsin tedrici olarak uzatılması ise diğer bir yöntemdir. İki aşamalı bu cerrahi yöntemde, iki teknik tanımlanmıştır. Birincisinde, suprapatellar bölgeden uygulanan traksiyon ile kuadriseps kasındaki kontraktür açılır ve sonrasında cerrahi olarak tespit edilir (Şekil 1). ${ }^{[6]}$ ikincisinde ise kuadriseps kasındaki kontraktür ve kırık hattındaki ayrışmaya ilk 


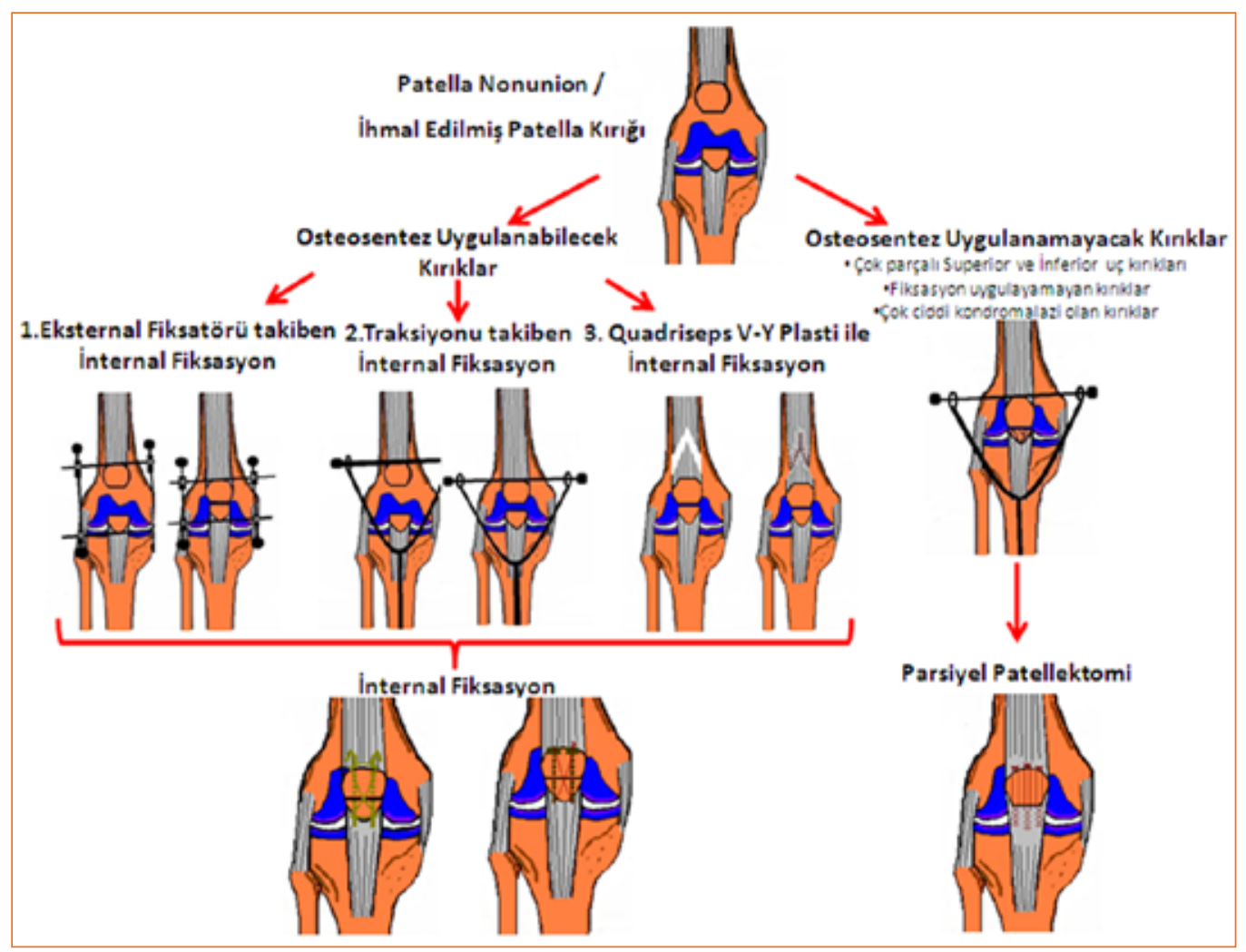

Şekil 1. Ihmal edilmiş primer tespiti yapılamayan ayrışmış kırıklarda uygulanabilecek cerrahi yöntemler.

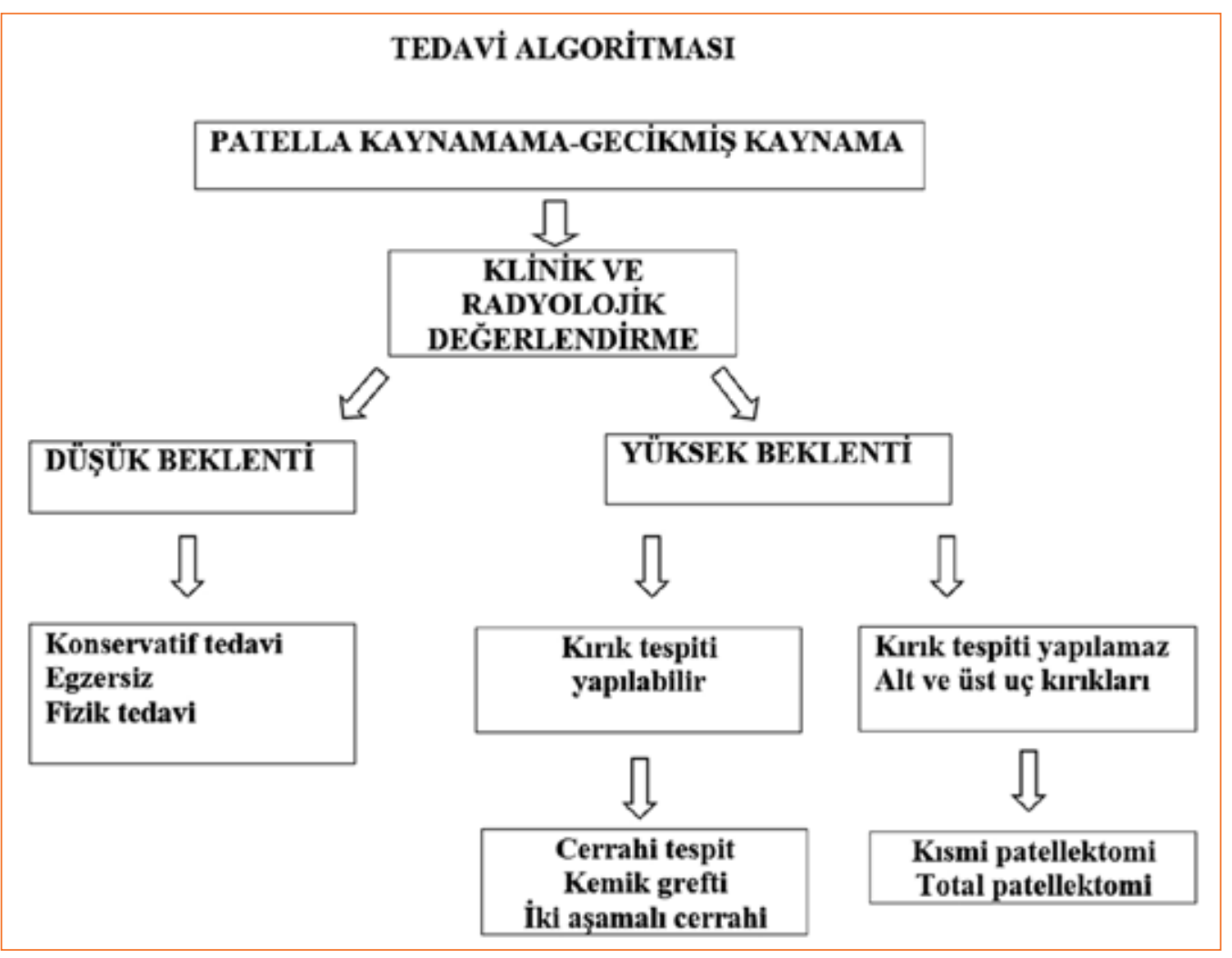

Şekil 2. Patella kırıklarında kaynamama ve gecikmiş kaynamada izlenebilecek cerrahi tedavi algoritması. 
önce eksternal fiksatör ile supra ve infrapatellar bölgelerden tedrici kompresyon yapılır; sonrası cerrahi tespittir (Şekil 1). ${ }^{[17]}$

Patella kırıklarında kaynamama ve gecikmiş kaynama nadir görülür. Kaynamamada, kırık tipi, yaş, cinsiyet ve yetersiz tespit önemli rol oynar. Güçlü diz ekstansör mekanizması nedeniyle, kırık tedavisinde tercih edilecek tespit yöntemi, kırık iyileşmesi gerçekleşinceye kadar geçen süre içinde kırık parçaları arasında yeterli kompresyon sağlaması ve sistemin bütünlüğü bozulmamasıdır. Tedavide, öncelikle hastanın beklentileri ve fonksiyonel kapasitesi göz önüne alınmalıdır. Tedavide izlenebilecek algoritma, güncel literatür gözden geçirildiğinde, Şekil 2'de özetlenmeye çalışıımıştır. Cerrahi tedavide amaç, ekstansör mekanizmanın bütünlüğünü oluşturulması ve fonksiyonel kapasitenin arttırılmasıdır.

\section{KAYNAKLAR}

1. Larsen P, Court-Brown CM, Vedel JO, Vistrup S, Elsoe R. Incidence and Epidemiology of Patellar Fractures. Orthopedics 2016;39(6):e1154-8. Crossref

2. Volgas D, Dreger TK. The Use of Mesh Plates for Difficult Fractures of the Patella. J Knee Surg 2017;30(3):200-3. Crossref

3. Kadar A, Sherman H, GlazerY, Katz E, Steinberg EL. Predictors for nonunion, reoperation and infection after surgical fixation of patellar fracture. J Orthop Sci 2015;20(1):168-73. Crossref

4. Petrie J, Sassoon A, Langford J. Complications of patellar fracture repair: treatment and results. J Knee Surg 2013;26(05):309-12. Crossref

5. Melvin JS, Mehta S. Patellar fractures in adults. J Am Acad Orthop Surg 2011;19(4):198-207.

6. Garg P, Sahoo S, Satyakam K, Biswas D, Garg A, Mitra S. Patellar nonunions: Comparison of various surgical methods of treatment. Indian J Orthop 2012;46(3):304-11. Crossref
7. Paxinos O, Karamitros A, Douras P, Kouris N. Neglected patella nonunion successfully treated after 8 years by quadriceps distractive lengthening with a spanning unilateral external fixation system. Knee Surg Sports Traumatol Arthrosc 2017. Crossref

8. Nathan ST, Fisher BE, Roberts CS, Giannoudis PV. The management of nonunion and delayed union of patella fractures: a systematic review of the literature. Int Orthop 2011;35(6):791-5. Crossref

9. Dy CJ, Little MT, Berkes MB, Ma Y, Roberts TR, Helfet DL, Lorich DG. Meta-analysis of re-operation, nonunion, and infection after open reduction and internal fixation of patella fractures: J Trauma Acute Care Surg 2012;73(4):928-32. Crossref

10. Uvaraj NR, Mayil Vahanan N, Sivaseelam A, Mohd Sameer M, Basha IM. Surgical management of neglected fractures of the patella. Injury 2007;38(8):979-83. Crossref

11. Satku K, Kumar VP. Surgical management of non-union of neglected fractures of the patella. Injury 1991;22(2):108-10.

12. Klassen JF, Trousdale RT. Treatment of delayed and nonunion of the patella. J Orthop Trauma 1997;11(3):188-94.

13. Miller MA, Liu W, Zurakowski D, Smith RM, Harris MB, Vrahas MS. Factors predicting failure of patella fixation. J Trauma Acute Care Surg 2012;72(4):1051-5. Crossref

14. Bonnaig NS, Casstevens C, Archdeacon MT, Connelly C, Monaco N, WyrickJD, Le TT. Fix it or discard it? A retrospective analysis of functional outcomes after surgically treated patella fractures comparing ORIF with partial patellectomy. J Orthop Trauma 2015;29(2):80-4. Crossref

15. Shukla DR, Sems AS, Stuart MJ. Percutaneous dowel bone grafting of a patella nonunion in a football player. Orthopedics 2010;33(5):332-4. Crossref

16. Cusano A, Curry EJ, Marinko LN, Li X. Extensor Mechanism Reconstruction for Chronic Patellar Fracture. Orthopedics 2018;41(1):e145-50. Crossref

17. Tripathi SK, Pant A, Agarwal NK, Kumar S, Krishna V, Julfiqar $J$. Two staged surgery for gap non-union of patella fracture: a good alternative. Ann Int Med Dent Res 2016;2(6). Crossref 